\title{
Variability and resistance mutations in the hepatitis C virus NS3 protease in patients not treated with protease inhibitors
}

\author{
Luciana Bonome Zeminian1, Juliana Lara Padovani', Sílvia Maria Corvino', Giovanni Faria Silva², \\ Maria Inês de Moura Campos Pardini ${ }^{1,2}$, Rejane Maria Tommasini Grotto ${ }^{1 /+}$
}

${ }^{1}$ Laboratório de Biologia Molecular, Divisão Hemocentro ²Departamento de Clínica Médica, Faculdade de Medicina de Botucatu, Universidade Estadual Paulista Júlio de Mesquita Filho, Botucatu, SP, Brasil

The goal of treatment of chronic hepatitis $C$ is to achieve a sustained virological response, which is defined as exhibiting undetectable hepatitis C virus (HCV) RNA levels in serum following therapy for at least six months. However, the current treatment is only effective in 50\% of patients infected with HCV genotype 1, the most prevalent genotype in Brazil. Inhibitors of the serine protease non-structural protein 3 (NS3) have therefore been developed to improve the responses of HCV-infected patients. However, the emergence of drug-resistant variants has been the major obstacle to therapeutic success. The goal of this study was to evaluate the presence of resistance mutations and genetic polymorphisms in the NS3 genomic region of HCV from 37 patients infected with HCV genotype 1 had not been treated with protease inhibitors. Plasma viral RNA was used to amplify and sequence the HCV NS3 gene. The results indicate that the catalytic triad is conserved. A large number of substitutions were observed in codons 153, 40 and 91; the resistant variants T54A, T54S, V55A, R155K and A156T were also detected. This study shows that resistance mutations and genetic polymorphisms are present in the NS3 region of HCV in patients who have not been treated with protease inhibitors, data that are important in determining the efficiency of this new class of drugs in Brazil.

Key words: HCV genotype 1a - NS3 protease mutations - protease inhibitors

The desired outcome of the treatment for hepatitis $\mathrm{C}$ virus (HCV) infection is a sustained virologic response (SVR), i.e., a persistent undetectable viral load for six months following the end of treatment (Zeuzem et al. 2004).

Although major advances have been achieved with the use of pegylated interferon, which has resulted in a significant improvement in the percentage of SVR (Zeuzem et al. 2004), effective anti-HCV therapy has only been achieved in $50 \%$ of carriers infected with genotype 1 . Therefore, new drugs have been studied, termed direct-acting antiviral agents, which include the non-structural protein 3 (NS3) protease inhibitors of the HCV virus (Thompson \& McHuntchison 2009).

NS3 is composed of both a DExH/D-box protein superfamily of the helicase domain and a trypsin/chymotrypsin family of the serine protease domain (Hahm et al. 1995, Kim et al. 1996, Love et al. 1996) and has a molecular weight of $67 \mathrm{kDa}$. NS3 is responsible for the cleavage of the viral polyprotein during the HCV replication cycle (Penin et al. 2004).

NS3 serine protease inhibitors employ competitive inhibition to block the action of the NS3 serine protease and, consequently, prevent the replication of HCV (de Francesco \& Carfi 2007). This type of drug has already been demonstrated to have a potent antiviral efficacy, reducing the number of viral copies in a patient during

+ Corresponding author: regrotto@uol.com.br

Received 10 January 2012

Accepted 4 October 2012 early treatment (Thompson \& McHuntchison 2009) and the first protease inhibitor, boceprevir, was approved for clinical use in 2011 (FDA 2011). Other such drugs have recently been tested in the development phase of drug discovery and the results have been promising in the United States and Europe, mainly in untreated patients infected with genotype 1 (Kieffer et al. 2007, McHuntchison et al. 2007).

However, the use of these target-specific drugs may lead to the emergence of resistant variants (Kieffer et al. 2007). Studies have demonstrated that some amino acid substitutions can alter the three-dimensional structure of the NS3 serine protease and result in changes in the charge of the protein, such as the substitutions Q68H, C97R, S174D and P131H, which can modify the interactions between different protein residues. However, the perpetuation of the specific substitutions is dependent on the extent of tolerance the virus has to the change. For example, amino acid substitutions in the catalytic triad lead to the loss of enzymatic activity, which destroys protein function. Therefore, viruses with this specific mutation would fail to perpetuate (Vallet et al. 2005).

Recent studies examining patients who used boceprevir have demonstrated the presence of mutations that have previously been associated with resistance to NS3 serine protease inhibitors such as sites V36, T54, V55, R155, A156 and V170 (Susser et al. 2009). Moreover, other resistant variants have been identified in vitro (T54A, $\mathrm{A} 156 \mathrm{~S} / \mathrm{T}, \mathrm{V} 170 \mathrm{~A})$ and in vivo $(\mathrm{V} 36 \mathrm{~A} / \mathrm{L} / \mathrm{M}, \mathrm{F} 43 \mathrm{C} / \mathrm{S}$, T54A/S, R155K/Q/T/M, A156S, V170A/T) (Tong et al. 2006, 2008, Susser et al. 2008, Qiu et al. 2009).

Notably, resistant mutants may already be present in minor populations at a frequency of less than $1 \%$, forming "quasispecies" in infected patients ( $\mathrm{Lu}$ et al. 2007, 
Cubero et al. 2008). These mutants can then rapidly emerge after only a few days of treatment (Kieffer et al. 2007, Sarrazin et al. 2007). However, some resistance mutations have already been detected in the major virus populations in patients who have not been treated with protease inhibitors (Colson et al. 2008).

The presence of virus-harbouring resistance mutations in patients who have not been treated with protease inhibitors is still controversial. Although some studies have reported a frequency of resistance mutations of less than 1\% (Lu et al. 2007, Bartels et al. 2008, Cubero et al. 2008), others have demonstrated a frequency that oscillates between 0.3-2.8\% (Kuntzen et al. 2008). Few studies have been conducted in Brazil and currently, there is only one study, which was conducted in Rio de Janeiro (RJ), that has reported the presence of a subtype la virus with a T54S mutation at a frequency of $4.1 \%$. Although a V170I substitution has not yet been associated with resistance, it was detected in $98 \%$ of samples (Peres-da-Silva et al. 2010).

Thus, with the availability of this new drug class for $\mathrm{HCV}$ treatment, detecting resistant variants among the quasispecies in infected patients may be a very important tool for evaluating and monitoring the efficacy of the therapy.

The goal of this study was to survey the presence of resistant mutations and other substitutions in the NS3 serine protease in patients with chronic hepatitis $\mathrm{C}$ who had not been treated with this class of drugs in order to evaluate the primary resistance of the viral population to $\mathrm{HCV}$ protease inhibitors.

\section{SUBJECTS, MATERIALS AND METHODS}

Aliquots of ethylenediamine tetraacetic acid-anticoagulated peripheral venous blood were collected from $37 \mathrm{HCV}$-infected patients being treated at the Department of Internal Medicine, Gastroenterology Division, Botucatu Medical School (FMB), São Paulo State University (UNESP), Botucatu, São Paulo, Brazil, in 2010. The inclusion criteria consisted of an HCV genotype 1a viral infection, detectable levels of viral RNA in the serum and a signed informed consent form. The exclusion criteria consisted of being hepatitis B virus or human immunodeficiency virus (HIV)-seropositive or the presence of other hepatic diseases. The characteristics of the patients included in this study are summarised in Table I. The study was approved by the Research Ethical Committee of the FMB, UNESP.

Plasma RNA was isolated using a QIAamp ${ }^{\circledR}$ Viral RNA Mini kit (QIAGEN, Valencia, CA, USA) (ebiotrade.com/ buyf/productsf/qiagen/1010446_qavrna_mini.pdf.) and was then used to amplify the $\overline{\mathrm{HCV}} \mathrm{NS} \overline{3}$ genomic region by reverse transcription-polymerase chain reaction (PCR) using Platinum Taq DNA Polymerase (Life Technologies, USA) according to the manufacturer's specifications and the primers described by de Carvalho-Mello et al. (2010). PCR products were sequenced using Big Dye ${ }^{\mathrm{TM}}$ Terminator Cycle Sequencing v3.1 (Applied Biosystems) and the electrophoresis was performed in $4.75 \%$ denaturing polyacrylamide gels in an ABI 377 sequencer (Applied Biosystems) according to the manufacturer's specifications using the same primers as used in the PCR reactions.
TABLE I

Demographic, clinical and virological characteristics of infected patients by hepatitis $\mathrm{C}$ virus (HCV) subtype 1a included in this study $(\mathrm{n}=37)$

\begin{tabular}{lc}
\hline Characteristics & $\mathrm{n}(\%)$ \\
\hline Age (years) (IQR) & $47(40-54)$ \\
Gender (male) & $27(72.97)$ \\
Treatment & \\
$\quad$ Naïve & $9(24.32)$ \\
Pegylated interferon and ribavirin & $28(75.68)$ \\
Fibrosis degree & \\
Light to moderate (F0, F1, F2) & $18(48.65)$ \\
Advanced (F3, F4) & $15(40.54)$ \\
Non performed & $4(10.81)$ \\
\hline
\end{tabular}

IQR: interquartil range

The chromatograms were evaluated with the software Phred (Ewing et al. 1998, Ewing \& Green 1998) using a quality score of 20. Resistance codons were identified by aligning them with the reference sequences of the NS3 region of HCV genotype 1a (AF009606, NC 004102, AF011751, AF011753, AF011752, AF290978, AFF11950, AF271632, AF511948, AF511949, AY695436, AY695437, AB520610,AY956465,AY956468,AY956466,AY956469, AY615798, AY956464, AJ278830, AY956463), available in the database of the Hepatitis C Virus Database Project (hcv.lanl.gov/content/index) and with the reference sequence of the complete HCV-1 genome (access M62321) available in GenBank (ncbi.nlm.nih.gov/), the program CLUSTAL X (Higgens et al. 1996).

\section{RESULTS}

The results of the resistance mutation and genetic polymorphism analysis for the 37 samples analysed are shown in Figure. In general, 315 substitutions were observed in the samples analysed; however, there was a notable conservation of the catalytic triad, which consists of histidine, aspartic acid and serine residues at positions $97,99,145$ and 149. In addition, a large number of substitutions were observed at codons 153 (94.6\%), 40 (67.5\%) and $91(67.5 \%)$.

Table II lists the substitutions according to the physicochemical characteristics of the change.

For the previously documented resistance mutations, seven $(18.9 \%)$ samples encoded resistant variants, including the mutations T54A, T54S, V55A and R155K, which were detected at a frequency of $2.7 \%$ and A156T, which was detected at a frequency of $5.4 \%$ in the population studied.

\section{DISCUSSION}

The introduction of protease inhibitors (FDA 2011) constitutes a major breakthrough in the treatment of chronic hepatitis C. However, the emergence of resistant variants, which are present as viral quasispecies in infected patients (Hammer et al. 2006), constitutes an obstacle to achieving SVR (Colson et al. 2008). Thus, 


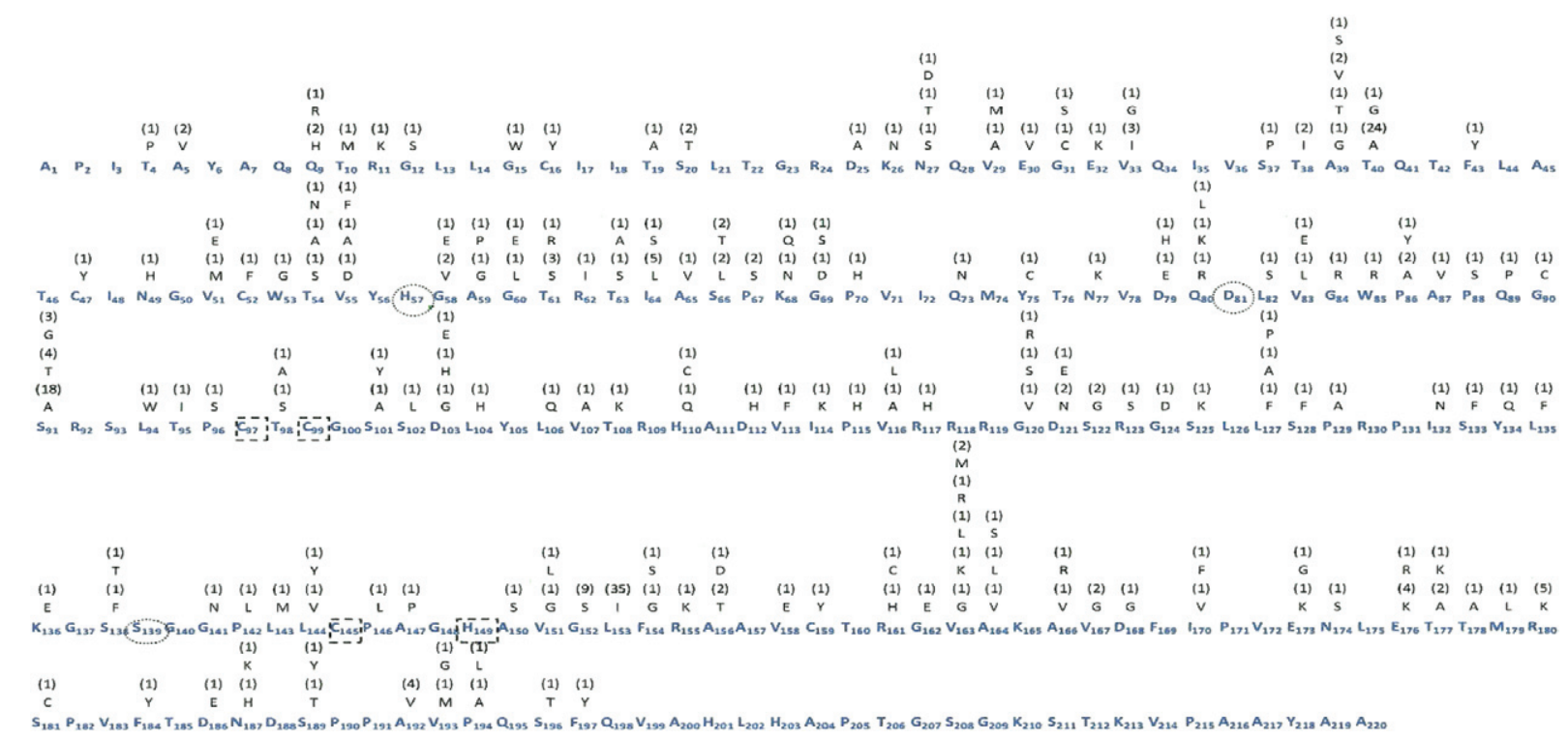

Frequency of amino acid substitutions in the non-structural protein 3 (NS3) region of hepatitis C virus (HCV) genotype 1a. The consensus sequence of amino acids is represented in blue. The subscript number at right refers to the position of the amino acid in the protein. Above each amino acid is represented the substitution and its absolute frequency. The highlighted numbers are the catalytic triad (black circles) and the residues linked to zinc (dotted square).

an evaluation of the presence of such variants in patients who have not been treated with this class of drugs is now particularly important.

The present study showed that the frequency of mutations associated with resistance was $18.9 \%$, which is inconsistent with the results of previous studies. However, when only individual frequencies of a mutation are considered, including T54A, T54S, V55A, R155K (2.7\%) and $\mathrm{A} 156 \mathrm{~T}$ (5.4\%), the results are similar to those reported in the literature (Bartels et al. 2008, Kuntzen et al. 2008, Peres-da-Silva et al. 2010).

The mutations in codons 54, 55, 155 and 156 encountered in the present study have previously been shown to be associated with resistance to boceprevir and telaprevir in patients undergoing treatment (Zeuzem et al. 2005a, b, Tong et al. 2006, 2008), but only the mutations in codons 54 and 155 have previously been reported in patients who had not been treated with protease inhibitors (Kuntzen et al. 2008). The substitution T54S, which had a frequency of $2.7 \%$, was previously reported at a frequency of $4.1 \%$ in $\mathrm{HCV}$ subtype la variants in RJ (Peres-da-Silva et al. 2010), suggesting that this substitution is already present in Brazilian variants even in the absence of selective drug pressure.

The mutation R155K alone does not appear to completely compromise the action of the drugs, but when combined with other substitutions, it may inhibit drug action (Sarrazin et al. 2007). Variants with this mutation have already been described in patients who have not been treated with protease inhibitors and show a fitness level comparable to that of the wild type (Colson et al. 2008), which is not expected for resistant variants (Sarrazin et al. 2007), suggesting that carriers with an R155K variant may be considered candidates for treatment failure with protease inhibitors.
In addition to the changes previously correlated with resistance, 315 additional amino acid substitutions were identified in the NS3 region, which constitutes a much larger number than what could be reasonably attributed to technical artefacts. A high-fidelity Taq DNA polymerase with proofreading activity can be used to precisely analyse quasispecies, thus minimising substitutions that may occur due to the incorporation of errant nucleotides during amplification (Malet et al. 2003).

Some substitutions may potentially disrupt the three-dimensional structure of NS3 protease, resulting in changes in an amino acid's electrical charge and, consequently, the electrostatic interactions between residues (Vallet et al. 2005). Of the changes detected in the resistance codons, only the substitutions T54N and I170V did not alter the physicochemical characteristics of the amino acid compared to the original amino acid. However, the implication of these alterations in resistance remains unclear because previously described resistance mutations have already been reported that have substitutions with the same or similar physicochemical characteristics as the wild-type amino acid.

Notably, there was a higher occurrence of substitutions in the codons $153(94.6 \%), 40(67.5 \%)$ and 91 $(67.5 \%)$, which have rarely been reported in the literature (Vallet et al. 2005). The substitutions T40A and S91A involve changes in the amino acid's electrical charge and position 91 should be studied further because of its close proximity to the residues in the catalytic triad.

The substitution L153I does not lead to a change in the amino acid's electrical charge. However, based on its high frequency in the population studied, this substitution may be a regional genetic polymorphism. Notably, $24.3 \%$ of the samples that harboured an L153I substitution also harboured a G152S substitution, which should 


\section{TABLE II}

Physicochemical characteristics of the found substitutions on analyzed samples of infected patients by hepatitis C virus (HCV) genotype 1a ( $\mathrm{n}=37)$

\begin{tabular}{|c|c|}
\hline Physicochemical characteristics & Substitutions \\
\hline Polar to polar & $\begin{array}{l}\text { S20T, N27S, N27T, T54S, T54N, T61S, T63S, S66T, } \\
\text { Q73N, S91T, T98S, S138T, N174S, S181C, S189T, S196T }\end{array}$ \\
\hline Polar to non-polar & $\begin{array}{l}\text { T4P, T10M, T19A, S37P, T38I, T40A, T40G, T54A, T63A, S66L, Q80L, } \\
\text { Q89P, S91A, S91G, T95I, T98A, S101A, S102L, S122G, C145G, T177A, T178A }\end{array}$ \\
\hline Polar to neutral-polar & C16Y, C47Y, C52F, S101Y, S128F, S133F, S138F, C159Y, S189Y \\
\hline Polar to acid & N27D \\
\hline Polar to basic & $\begin{array}{l}\text { Q9R, Q9H, S20T, N49H, T61R, Q80R, N77K, Q80K, } \\
\text { T108K, S125K, T177K, N187H, N187K }\end{array}$ \\
\hline Neutral-polar to neutral-polar & F43Y, F184Y, F197Y \\
\hline Neutral-polar to polar & Y75C, Y134Q, F154S \\
\hline Neutral-polar to non-polar & W53G \\
\hline Neutral-polar to basic & W85R \\
\hline Non-polar to non-polar & $\begin{array}{l}\text { A5V, V29A, V29M, V33G, V33I, A39G, A39V, V51M, V55A, G58V, A59G, A59P, G60L, } \\
\text { I64L, A65V, V83L, P86A, P86A, A87V, V107A, V116L, V116A, G120V, L127A, L127P, } \\
\text { P129A, P142L, L143M, L144V, P146L, A147P, V151G, V151L, L153I, V163G, V163L, V163M, } \\
\text { A164V, A164L, A166V, V167G, I170V, M179L, A192V, V193G, V193M, P194A, P194L }\end{array}$ \\
\hline Non-polar to polar & $\begin{array}{l}\text { G12S, G31C, G31S, A39T, A39S, I64S, P67S, G69S, L82S, P88S, G90C, P96S, L106Q, } \\
\text { G120S, I132N, G141N, A150S, G152S, A156T, A164S }\end{array}$ \\
\hline Non-polar to neutral-polar & G15W, V55F, P86Y, L94W, V113F, L127F, L135F, L144Y, I170F \\
\hline Non-polar to acid & V51E, V55D, G58E, G60E, G69D, V83E, G124D, A156D, V158E, G162E \\
\hline Non-polar to basic & P70H, G84R, L104H, I114K, G120R, P155H, V163R, V163K, A166R, \\
\hline Basic to basic & R11K, R117H, R155K, R161H, R180K \\
\hline Basic to acid & $\mathrm{K} 136 \mathrm{E}$ \\
\hline Basic to polar & K26N, K68N, K68Q, H110Q, H110C, R123S, R161C \\
\hline Basic to non-polar & R62I \\
\hline Acid to acid & D79E, D103E, D121E, D186E \\
\hline Acid to basic & E32K, D79H, D103H, D112H, E173K, E176R, E176K \\
\hline Acid to polar & D121N \\
\hline Acid to non-polar & D25A, E30V, D103G, D168G, D168G, E173G \\
\hline
\end{tabular}

be examined in more detail because it may suggest a probable association of substitutions.

The development of new HCV protease inhibitors has been difficult when one considers both the antiviral potency of the drugs and the resistance profiles of the virus variants (Halfon \& Locarnini 2011). This type of information was not available prior to the introduction of protease inhibitors used to treat HIV infections, which lead to difficulties in discerning between resistance mutations and natural viral polymorphisms (Vallet et al. 2005).

In conclusion, the data obtained in this study show the presence of resistance mutations and genetic polymorphisms in the NS3 region of $\mathrm{HCV}$ in patients who have not been treated with protease inhibitors. This information may help determine the efficacy of this new class of drugs in Brazil.

These results have been analysed based on the number of cases used and these conclusions are based only
HCV genotype 1a, which is circulating in the Botucatu region of Brazil.

\section{REFERENCES}

Bartels DJ, Zhou Y, Zhang EZ, Marcial M, Byrn RA, Pfeiffer T, Tigges AM, Adiwijaya BS, Lin C, Kwong AD, Kieffer TL 2008. Natural prevalence of hepatitis $\mathrm{C}$ virus variants with decreased sensitivity to NS3-4A protease inhibitors in treatment-naïve subjects. J Infect Dis 198: 800-807.

Colson P, Brouk N, Lembo F, Castellani P, Tamalet C, Gérolami R 2008. Natural presence of substitution R155K within hepatitis C virus NS3 protease from a treatment- naïve chronically infected patient. Hepatology 47: 766-767.

Cubero M, Esteban JI, Otero T, Sauleda S, Bes M, Esteban R, Guardia J, Quer J 2008. Naturally occuring NS3-protease-inhibitor resistant mutant A156T in the liver of an untreated chronic hepatitis C patient. Virology 370: 237-245.

de Carvalho-Mello IMVG, Medeiros Filho JE, Gomes-Gouvêa MS, Malta F de M, De Queiróz ATL, Pinho JRR, Carrilho FJ 2010. 
Molecular evidence of horizontal transmission of hepatitis C virus within couples. J Gen Virol 91: 691-696.

de Francesco R, Carfi A 2007. Advances in the development of new therapeutic agents targeting the NS3-4A serine protease or the NS5B RNA-dependent RNA polymerase of the hepatitis C virus. Adv Drug Deliv Rev 59: 1242-1262.

Ewing B, Green P 1998. Base-calling of automated sequencer traces using Phred. II. Error probabilities. Genome Res 8: 175-194.

Ewing B, Hillier La Deana, Wendl MC, Green P 1998. Base-calling of automated sequencer traces using Phred. I. Accuracy assessment. Genome Res 8: 175-185.

FDA - Food and Drug Administration 2011. [homepage on the internet]. Hepatitis C experts sought for FDA Advisory Committee. Available from: hivandhepatitis.com/help_c/news/2010/1210_2010_a. html, 2010.

Hahm B, Han DS, Back SH, Song OK, Cho MJ, Kim CJ, Shimotohno $\mathrm{K}$, Jang SK 1995. NS3-4A of hepatitis C virus is a chymotrypsinlike protease. J Virol 69: 2534-2539.

Halfon P, Locarnini S 2011. Hepatitis C virus resistance to protease inhibitors. J Hepatol 55: 192-206.

Hammer SM, Saag MS, Schechter M, Montaner JSG, Schooley RT, Jacobsen DM, Thompson MA, Carpenter CCJ, Fischl MA, Gazzard BG, Gatell JM, Hirsch MS, Katzenstein DA, Richman DD, Vella S, Yeni PG 2006. Treatment for adult HIV infection: 2006 recommendations of the international AIDS society - USA panel. JAMA 296: 827-843.

Higgens DG, Thompson JD, Gibson TJ 1996. Using CLUSTAL for multiple sequence alignments. Methods Enzymol 266: 383-402.

Kieffer TL, Sarrazin C, Miller JS, Welker MW, Forestier N, Reesink HW, Kwong AD, Zeuzem S 2007. Telaprevir ad pegylated interferon-alpha-2a inhibit wild-type and resistant genotype 1 hepatitis $\mathrm{C}$ virus replication in patients. Hepatology 46: 631-639.

Kim JL, Morgenstern KA, Lin C, Fox T, Dwyer MD, Landro JA, Chambers SP, Markland W, Lepre CA, O'Malley ET, Harbeson SL, Rice CM, Murcko MA, Caron PR, Thomson JA 1996. Crystal structure of the hepatitis $\mathrm{C}$ virus NS3 protease domain complexed with a synthetic NS4A cofactor peptide. Cell 87: 343-355.

Kuntzen T, Timm J, Berical A, Lennon N, Berlin AM, Young SK, Lee B, Heckerman D, Carlson J, Reyor LL, Kleyman M, McMahon CM, Birch C, Schulze Zur, Wiesch J, Ledlie T, Koehrsen M, Kodira C, Roberts AD, Lauer GM, Rosen HR, Bihl F, Cerny A, Spengler U, Liu Z, Kim AY, Xing Y, Schneidewind A, Madey MA, Fleckenstein JF, Park VM, Galagan JE, Nusbaum C, Walker BD, Lake-Bakaar GV, Daar ES, Jacobson IM, Gomperts ED, Edlin BR, Donfield SM, Chung RT, Talal AH, Marion T, Birren BW, Henn MR, Allen TM 2008. Naturally occurring dominant resistance mutations to hepatitis $\mathrm{C}$ virus protease and polymerase inhibitors in treatment-naïve patients. Hepatology 48: 1769-1778.

Love RA, Parge HE, Wickesham JA, Hostomsky Z, Habuka N, Moomaw EW, Adachi T, Hostomska Z 1996. The crystal structure of hepatitis C virus NS3 proteinase reveals a trypsin-like fold and a structural zinc binding site. Cell 87: 331-342.

Lu L, Dekhtyar T, Masse S, Pithawalla R, Krishnan P, He W, Ng T, Koev G, Stewart K, Larson D, Bosse T, Wagner R, Pilot-Matias T, Mo H, Molla A 2007. Identification and characterization of mutations conferring resistance to an HCV RNA-dependent RNA polymerase inhibitor in vitro. Antiviral Res 76: 93-97.

Malet I, Belnard M, Agut H, Cahour A 2003. From RNA to quasispecies: a DNA polymerase with proofreading activity is highly recommended for accurate assessment of viral diversity. $J$ Virol Methods 109: 161-170.
McHutchison JG, Everson GT, Gordon S, Jacobson I, Kauffman R, McNair L, Muir AJ 2007. Results of an interim analysis of a phase 2 study of telaprevir (VX-950) with peginterferon-alfa-2a and ribavirin in previously untreated subjects with hepatitis C. Annual meeting of the European association for the study of the liver. J Hepatol 46 (Suppl. 1): S296.

Penin F, Dubuisson J, Rey FA, Moradpour D, Pawlotsky JM 2004. Structural biology of hepatitis C virus. Hepatology 39: 5-19.

Peres-da-Silva A, de Almeida AJ, Lampe E 2010. Mutations in hepatitis C virus NS3 protease domain associated with resistance to specific protease inhibitors in antiviral therapy naïve patients. Arch Virol 155: 807-811.

Qiu P, Sanfiorenzo V, Curry S, Guo Z, Liu S, Skelton A, Xia E, Cullen C, Ralston R, Greene J, Tong X 2009. Identification of HCV protease inhibitor resistance mutations by selection pressure-based method. Nucleic Acids Res 37: e34.

Sarrazin C, Kieffer TL, Bartels D, Hanzelka B, Muh U, Welker M, Wincheringer D, Zhou Y, Chu H-M, Lin C, Weegink C, Reesink H, Zeuzem S, Kwong AD 2007. Dynamic hepatitis C virus genotypic and phenotypic changes in patients treated with the protease inhibitor telaprevir. Gastroenterology 137: 1767-1777.

Susser S, Welker M, Zettler M, Wohnsland A, Hughes E, Ralston R, Tong X, Zeuzem S, Sarrazin C 2008. Clonal analysis of mutations selected in the HCV NS3 protease domain of genotype 1 non-responders treated with boceprevir (SCH503034). $J$ Hepatol 48 (Suppl. 2): S29.

Susser S, Welsch C, Wang Y, Zettler M, Domingues FS, Karey U, Hughes E, Ralston R, Tong X, Herrmann E, Zeuzem S, Sarrazin C 2009. Characterization of resistance to the protease inhibitor boceprevir in hepatitis $\mathrm{C}$ virus-infected patients. Hepatology 50: $1709-1718$

Thompson AJV, McHuntchison JG 2009. Antiviral resistance and specifically targeted therapy for HCV (STAT-C). $J$ Virol Hepat 16: 377-387.

Tong X, Bogen S, Chase R, Girijavallabhan V, Guo Z, Njoroge FG, Prongay A, Saksena A, Skelton A, Xia E, Ralston R 2008. Characterization of resistance mutations against HCV ketoamide protease inhibitors. Antiviral Res 77: 177-185.

Tong X, Chase R, Skelton A, Chen T, Wright-Minogue J, Malcolm BA 2006. Identification and analysis of fitness of resistance mutations against the HCV protease inhibitor SCH503034. Antiviral Res 70: 28-38.

Vallet S, Gouriou S, Nousbaum JB, Legrand-Quillien C, Goudeau A, Picard B 2005. Genetic heterogeneity of the NS3 protease gene in hepatitis $\mathrm{C}$ virus genotype 1 from untreated infected patients. J Med Virol 75: 528-537.

Zeuzem S, Hultcrantz R, Bourliere M, Goeser T, Marcellin P, Sanchez-Tapias J, Sarrazin C, Harvey J, Brass C, Albrecht J 2004. Peginterferon alfa- $2 b$ plus ribavirin for treatment of chronic hepatitis $\mathrm{C}$ in previously untreated patients infected with $\mathrm{HCV}$ genotypes 2 or $3 * 1, * 2$. J Hepatol 40: 993-999.

Zeuzem S, Sarrazin C, Rouzier R, Tarral A, Brion N, Forestier N, Gupta S, Deckman D, Fellows K, Hussain M, Cutler D, Zhang J 2005a. Anti-viral activity of SCH 503034, a HCV protease inhibitor administered as monotherapy in HCV-1 patients refractory to pegylated interferon (PEG-INF- $\alpha$ ). Hepatology 42: 233A-234A.

Zeuzem S, Sarrazin C, Wagner F, Rouzier R, Forestier N, Gupta S, Hussain M, Shah A, Cutler D, Zhang J 2005b. Combination therapy with HCV protease inhibitor SCH 503034, plus PEG-intron in hepatitis $\mathrm{C}$ genotype-1 PEG-intron non-responders: phase $1 \mathrm{~b}$ results. Hepatology 42: 276A-277A. 